\title{
Factors Influencing the Reactions of Relatives of Arrested Patients Receiving CPR and Reactions to the News of Their Deaths
}

\author{
Tufan Yıldııım, Behçet Al, Suat Zengin, Mustafa Boğan, Mustafa Sabak, Cuma Yıldırım, Şevki Hakan Eren \\ Department of Emergency Medicine, Gaziantep University School of Medicine, Gaziantep, Turkey
}

Cite this article as: Yıldıım T, Al B, Zengin S, Boğan M, Sabak M, Yıldırım C, et al. Factors Influencing the Reactions of Relatives of Arrested Patients Receiving CPR and Reactions to the News of Their Deaths. Eurasian J Emerg Med 2017; 16: 112-8

\begin{abstract}
Aim: Although various studies in the literature have focused on the delivery of bad news, data originating from the emergency services about the factors influencing relatives' reactions are insufficient. To evaluate the reactions of patients' relatives to the receipt of bad news in the emergency department and the factors influencing these reactions.
\end{abstract}

Materials and Methods: The study was performed in the Gaziantep University Faculty of Medicine Department of Emergency Medicine (Group 1) and the emergency departments of state hospitals in Gaziantep (Group 2) between May 2014 and May 2015. The physicians in Group 1 had received training in communicating bad news to relatives. The physicians in Group 2 had not received such training. The approaches of the physicians to the delivery of bad news and the reactions of the patients' relatives were recorded in prepared forms.

Results: Each group included 100 patients who underwent resuscitation. The rates of briefing relatives and information provision about the possibility of arrest were higher in Group 1. The main reaction of the relatives in Group 1 was crying, whereas the relatives in Group 2 had multiple negative reactions. Many of the relatives in Group 2 committed violence in order to see their loved ones during Cardiopulmonary Resuscitation (CPR). When the data for both groups were combined, the rates of negative responses were highest for cases of unexpected death and male patients.

Conclusion: The degree of affinity to the patient, the frequency and type of information provided to relatives during and after resuscitation, and informing relatives after allowing them into the resuscitation room to see their loved ones affected relatives' reactions.

Keywords: Cardiac arrest patient, emergency care, bad news, patient's relatives, factors affecting reactions

\section{Introduction}

Bad news, which is any news that threatens an individual's physical and emotional well-being and adversely affects that person's life, can potentially lead to unexpected reactions (1). It is painful to know that someone's death is close. In our daily lives, we try to ignore death, but it remains a reality that affects thousands of households every day (2). Such news results in different reactions and responses (2) as the person strives to cope with the new situation. Different definitions and perceptions of death in diverse cultures, societies, and disciplines, in addition to the individual's character, age, and religion, may dictate the reactions to news of a death (3). Explanations of death that draw on loss of an organism's ability to renew itself do not have a provision in the hearts, minds, hearts, and emotions of a patient's relatives.

Emergency departments are the places that individuals most commonly hear the devastating news of their relative's death. The death may negatively affect emergency service staff, especially the physicians who have to deliver the bad news. Emergency service staff may not feel ready or able to cope with relatives' intense responses and fear being blamed for the death $(4,5)$.

The most common suggestions for coping with this sad experience are creating opportunities for the patients' relatives to witness 
the resuscitation and educating hospital staff in the delivery of bad news, so that they can do so in a gentle, empathetic, and humane way $(6,7)$. Delivering bad news in an unprofessional way can expose emergency service staff to violence, and it can cause psychological damage and occupational burnout (8-10). Emergency staff can address this challenge by engaging in kind and reassuring communication with relatives and providing appropriate information based on their knowledge and expectations of normal emotional responses in such situations.

Based on a review of the literature, it is evident that there have been no thorough studies of the reactions of relatives to news of a patient's death and the factors influencing these reactions. The aim of this study was to examine the reactions of relatives to the news of the death of a loved one and the factors that positively or negatively affected their reactions.

\section{Materials and Methods}

\section{Population and sample}

This was a prospective study of the emergency services of Gaziantep University Şahinbey Research and Application Hospital (Group 1) and two state hospitals (Dr. Ersin Arslan Hospital and Şehitkamil State Hospital) (Group 2) between 1 May 2014 and 1 May 2015. The study was approved by Gaziantep University Faculty of Medicine Ethics Committee (Date: 14.05.2012; approval no: 14.05.2012/203). The study protocol was executed according to the Helsinki Declaration.

\section{Study Centers}

\section{Group 1: Gaziantep University Şahinbey Research and} Application Hospital (adult emergency service)

- There were four emergency medicine physicians and 20 assistants (eight of whom had at least two years of experience) on duty.

- $\quad$ There were 20 examination stretchers, 10 observation beds, 2 resuscitation rooms, 1 surgical intervention room, and 1 critical care room.

- $\quad$ Between May 2014 and May 2015, 113,000 patients were admitted to the emergency department for health care. Of those, 3500 (3\%) were trauma patients. All the patients were older than 16 years (patients younger than 16 yearswere admitted to the children's emergency department).

- All Cardiopulmonary Resuscitation (CPR) was performed by emergency medicine physicians and assistants.

- During the 12-month study period, 150 patients $(0.1 \%)$ underwent CPR, and CPR was unsuccessful (patients died) in 110 (73.3\%) of those cases.

\section{Group 2: Gaziantep Dr. Ersin Arslan Hospital and Şehitkamil State Hospital}

- $\quad$ There were 5 emergency medicine physicians and 13 general practitioners in Dr. Ersin Arslan State Hospital and 7 emergency medicine physicians and 15 general practitioners in Şehitkamil State Hospital.

- There were 18 examination stretchers, 1 trauma room, 2 resuscitation rooms, and a 12-bed monitored area in Dr. Ersin Arslan State Hospital.
- There were 10 examination stretchers, 2 resuscitation rooms, a 30-bed monitored area, and 1 surgical intervention room in Şehitkamil State Hospital.

- Between May 2014 and May 2015, approximately 500,000 patients were admitted to Dr. Ersin Arslan State Hospital, and 440,000 patients were admitted to Şehitkamil State Hospital for diagnosis and treatment. Of those, $18,500(2 \%)$ were trauma patients, and the remainder had urgent internal problems.

- In both hospitals, adults and children were examined in the same emergency departments.

- $\quad$ During the 12-month study period, $720(0.07 \%)$ patients underwent CPR, and CPR was unsuccessful in 390 (54.2\%) of those cases.

Cardiopulmonary Resuscitation and advanced cardiac life support were performed in all patients based on American Heart Association guidelines (11). All the procedures took place in emergency service resuscitation rooms. In all cases, the attending physician delivered the news of the patient's death to the relatives.

\section{Inclusion criteria}

- $\quad$ Patients with cardiac arrest who were accompanied by relatives but passed away despite medical interventions.

Patients older than 16 years.

- $\quad$ Patients who were citizens of the Republic of Turkey.

- $\quad$ CPR procedures started and ended in the emergency department.

- $\quad$ CPR procedures performed by emergency medicine physicians or assistants with over two years of experience and trained in the delivery of bad news.

\section{Exclusion or disqualification criteria}

- $\quad$ Patients with cardiac arrest who were accompanied by relatives and lived after the intervention .

- Patients younger than 16 years.

- Patients who were not citizens of the Republic of Turkey.

- CPR procedures performed by general practitioners or assistants with fewer than two years of experience (we feel that the CPR delivered by this group is not as effective and may lead to an increased mortality rate in the patients treated by this group).

\section{Case selection}

The 12-month study (May 2014 to May 2015) consisted of patients who had cardiac arrest inside or outside the hospitals and died, despite prompt CPR and their relatives. The study was made up of two groups to investigate the impact of training in the delivery of bad news and the experience of the practitioner on relatives' reactions to being told of the death of a loved one.

\section{Group selection}

\section{Group 1}

Patients who had a cardiac arrest during observation or were admitted with cardiac arrest to Gaziantep University Faculty of Medicine Department of Emergency Medicine were included in Group 1. The doctors (four emergency medicine physicians and eight assistants with at least two years of emergency medicine experience) were informed about emergency crisis management, 
when and how to give information to relatives during resuscitation, and how to react to relatives' reactions. They were also shown a 90min slideshow, with case reports and videos of three real cases of cardiac arrest. This study lasted for two days in total (one day of briefing and debate, and one day of case presentation).They were reminded about the content of the slideshow prior to dealing with the cardiac arrest cases. Their assignments were repeated to them throughout the study. The information always was given to the family by the most senior doctor.

The medical personal provided the first briefing to the relatives outside the resuscitation room after a short examination of the patients. The second and third briefings were made in the resuscitation room after the relatives had seen their loved ones for $10 \mathrm{sec}$ during CPR. The last briefing took place in the resuscitation room just before ending the CPR after the relatives had entered the room and had seen their loved ones. This briefing was made in the presence of hospital security staff. It included an explanation of the interventions and standard statements, such as "patient did not respond to CPR, it would not have made any difference had the CPR been continued and it was appropriate to end the CPR." In addition, the relatives were informed that the deceased patient would be sent to the morgue. Condolences were given to all the relatives of the deceased patients.

\section{Group 2}

Patients (Only CPR performed by emergency medical physicians on subjects aged older than 16 years) who had cardiac arrest during observation or were admitted to Dr. Ersin Arslan State Hospital's and Şehitkamil State Hospital's (secondary hospitals) emergency departments with cardiac arrest were included in Group 2. CPR procedures performed by general practitioners and pre-hospital were not included. Unlike Group 1, Group 2 received no training or information on behavior patterns while delivering the news about the death of the patient to the relatives.

\section{Data collection, measuring the reactions, and comparison of the results}

A 21-question survey was prepared to evaluate the responses of the relatives and the duration and quality of the medical interventions. The following data were recorded: age, gender, present complaints, cause of arrest and conditions upon arrival to the hospital, expected/unexpected death, relatives' degree of affinity, number of present relatives, informing or not informing relatives, first reaction of relatives during cardiac arrest, duration of resuscitation, location where relatives were informed during and after resuscitation, identity of the person who delivered news of the death, and first reactions of the relatives. Furthermore, to eliminate confounding the forms were completed by four different emergency medicine technicians who were not aware of the differences between the groups. The between-group differences were compared.

Power analysis: Sample size was determined to detect a significant difference between expected negative reaction rates of relatives of arrest patients when informing was completed vs not completed. The expected negative reaction rates were $40 \%$ and $60 \%$, respectively. A minimum sample size for each group was determined as 97 for a $20 \%$ effect size $(\alpha=0.05,1-\beta=0.80)$. G power version 3.01 was used to perform the power analysis.
Table 1. Present diseases and conditions causing cardiac arrest, number of patient's relatives and degree of affinity

\begin{tabular}{|c|c|c|}
\hline & Group 1 & Group 2 \\
\hline \multicolumn{3}{|l|}{ Cause of arrest } \\
\hline $\begin{array}{l}\text { Acute phase of chronic disease } \\
\text { (COPD, leukemia, heart failure etc.) }\end{array}$ & 18 & 20 \\
\hline Trauma & 11 & 9 \\
\hline Cancer & 10 & 0 \\
\hline $\begin{array}{l}\text { Acute thrombosis } \\
\text { (MI, pulmonary embolism) }\end{array}$ & 28 & 31 \\
\hline Acute stroke & 4 & 0 \\
\hline $\begin{array}{l}\text { Major artery damage } \\
\text { (aortic dissection, artery cut etc.) }\end{array}$ & 0 & 3 \\
\hline Drug overdose & 11 & 6 \\
\hline Fatal arrhythmias (VF/VT) & 7 & 5 \\
\hline Aspiration related respiratory failure & 6 & 16 \\
\hline Other & 5 & 10 \\
\hline \multicolumn{3}{|l|}{ Number of relatives } \\
\hline 1 & 12 & 8 \\
\hline $2-5$ & 52 & 61 \\
\hline $6-10$ & 28 & 20 \\
\hline$>10$ & 8 & 11 \\
\hline
\end{tabular}

\section{Degree of affinity}

\begin{tabular}{|l|c|c|}
\hline First-degree relatives* & 27 & 18 \\
\hline Second degree relatives and friends & 8 & 13 \\
\hline Multiple first-degree relatives & 26 & 28 \\
\hline Multiple first and second degree relatives & 39 & 41
\end{tabular}

Duration of CPR

\begin{tabular}{|l|c|c|}
\hline$<20$ minutes & 4 & 13 \\
\hline $20-30$ minutes & 19 & 29 \\
\hline $30-50$ minutes & 70 & 48 \\
\hline$>60$ minutes & 7 & 10
\end{tabular}

Frequency of informing

\begin{tabular}{|l|l|l|}
\hline 10 minutes intervals & 32 & 10 \\
\hline 15 minutes intervals & 52 & 17 \\
\hline$>20$ minutes & 15 & 24
\end{tabular}

COPD: chronic obstructive pulmonary disease; VF: ventricular fibrillation; VT: ventricular tachycardia; MI: myocardial ischemia; CPR: cardiopulmonary resuscitation. *Spouse, child, sibling, parents

\section{Statistical analysis}

The study began in May 2014 and finished in May 2015 when sufficient numbers of cases (an average of 100 cases in each group) were available. The Statistical Package for Social Sciences (IBM SPSS Statistics; Armonk, NY, USA) 22.0 program was used to analyze the data. The correlation between the both groups was determined by using a Chisquare test. Statistical significance was accepted at a value of $p<0.05$. 
Table 2. Relatives' reactions before, during, and after CPR

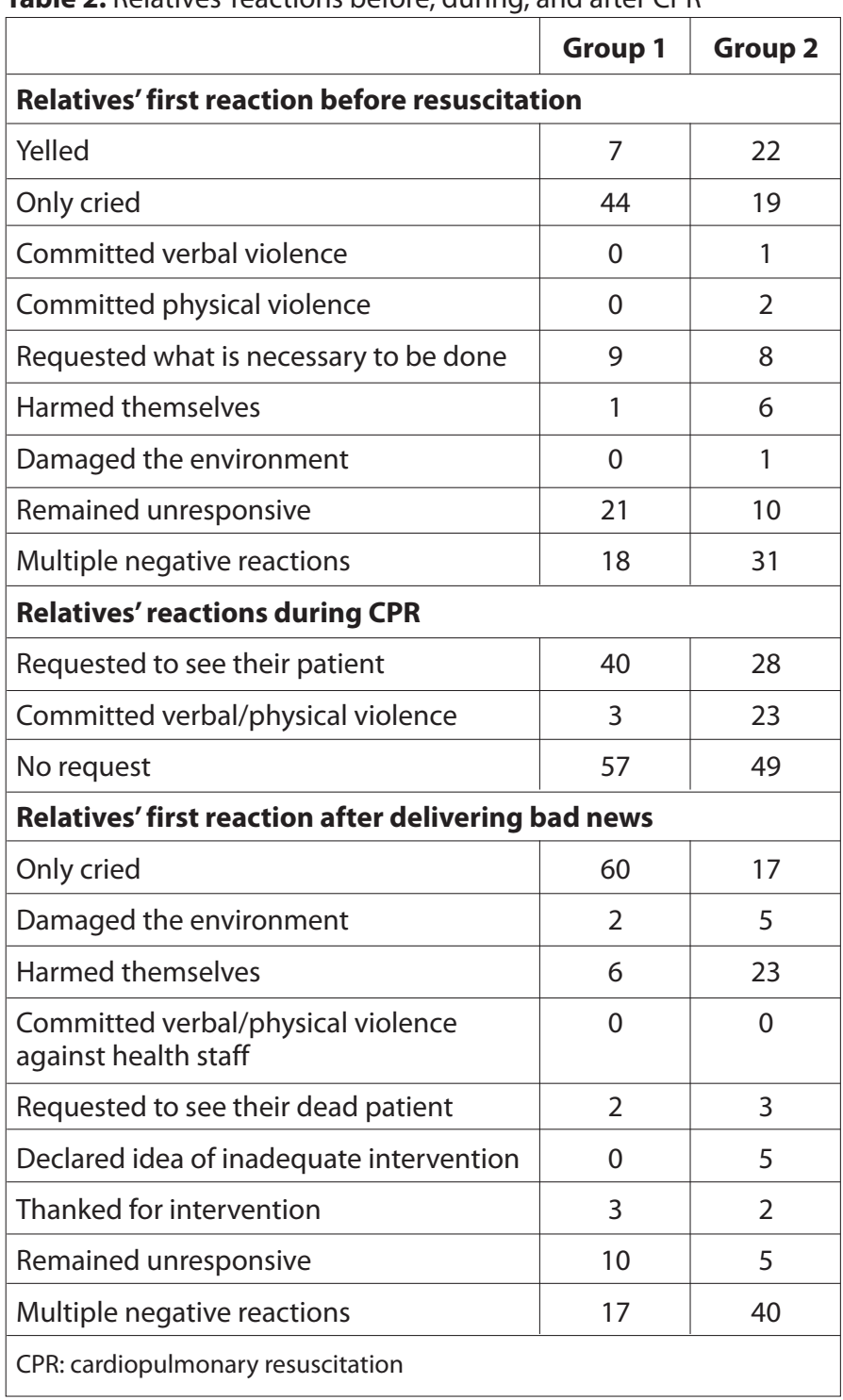

\section{Results}

During a twelve-month period150 of 113,000 (0.1\%) patients who were admitted to Gaziantep University Faculty of Medicine Department of Emergency Medicine underwent CPR. Of those, 100 $(0.09 \%)$ met the inclusion criteria and were included in Group 1. Fifty patients were excluded because they were not citizens of the Republic of Turkey.

During the same period, $538(0.08 \%)$ of 940,000 patients who were admitted to Dr. Ersin Arslan State Hospital's and Şehitkamil State Hospital's emergency departments underwent CPR. Of those, 438 CPR patients were not included because the CPR was administered by general practitioners $(n=238)$, the patients were not citizens of the Republic of Turkey $(n=97)$, or the patients were younger than 16 years $(n=103)$. One-hundred CPR patients who were treated by emergency medicine physicians were included in Group 2.

In the study, $34 \%$ of the patients were females, and $66 \%$ were males. Among those patients, 127 (63.5\%) were chronic but stable, $16(8 \%)$ had terminal diseases, and $57(28.5 \%)$ were disease-free. In
Table 3. Comparison of reactions of groups based on expected and unexpected death

\begin{tabular}{|c|c|c|c|c|}
\hline Groups & Reactions & $\begin{array}{l}\text { Expected } \\
\text { death }\end{array}$ & $\begin{array}{l}\text { Unexpected } \\
\text { death }\end{array}$ & Total \\
\hline & & n (\%) & n (\%) & n (\%) \\
\hline \multirow{8}{*}{$\begin{array}{l}\text { Group } 1 \\
p=0.027\end{array}$} & Only cried & $17(54.8)$ & $43(62.3)$ & $60(60)$ \\
\hline & $\begin{array}{l}\text { Damaged } \\
\text { the environment }\end{array}$ & $1(3.2)$ & $1(1.4)$ & $2(2)$ \\
\hline & Harmed themselves & - & $6(8.7)$ & $2(6)$ \\
\hline & $\begin{array}{l}\text { Asked permission } \\
\text { to see their patient }\end{array}$ & - & $2(2.9)$ & $2(2)$ \\
\hline & Thanked & $3(9.7)$ & - & $3(3)$ \\
\hline & $\begin{array}{l}\text { Remained } \\
\text { unresponsive }\end{array}$ & $3(9.7)$ & $7(10.1)$ & $10(10)$ \\
\hline & $\begin{array}{l}\text { Multiple negative } \\
\text { reactions }\end{array}$ & $7(22.6)$ & $10(14.5)$ & $17(17)$ \\
\hline & Total & $31(100)$ & $69(100)$ & $100(100)$ \\
\hline \multirow{9}{*}{$\begin{array}{l}\text { Group } 2 \\
p=0.002\end{array}$} & Only cried & $4(22.2)$ & $13(15.9)$ & $17(17)$ \\
\hline & $\begin{array}{l}\text { Damaged the } \\
\text { environment }\end{array}$ & $1(5.6)$ & $4(4.9)$ & $5(5)$ \\
\hline & Harmed themselves & $7(38.9)$ & $16(19.5)$ & $23(23)$ \\
\hline & $\begin{array}{l}\text { Asked permission } \\
\text { to see their patient }\end{array}$ & - & $3(3.7)$ & $3(3)$ \\
\hline & $\begin{array}{l}\text { Declared idea of } \\
\text { inadequate } \\
\text { intervention }\end{array}$ & $1(5.6)$ & $4(4.9)$ & $5(5)$ \\
\hline & Thanked & - & $2(2.4)$ & $2(2)$ \\
\hline & $\begin{array}{l}\text { Remained } \\
\text { unresponsive }\end{array}$ & $4(22.2)$ & $1(1.2)$ & $5(5)$ \\
\hline & $\begin{array}{l}\text { Multiple negative } \\
\text { reactions }\end{array}$ & $1(5.6)$ & 39 (47.6) & $40(40)$ \\
\hline & Total & $18(100)$ & $82(100)$ & $100(100)$ \\
\hline
\end{tabular}

both groups, the most common cause of the cardiac arrest (29.5\%) was thrombosis (myocardial infarctions and pulmonary embolisms) in. The patients' diseases and causes of arrest are listed in Table 1.

The numbers of patients in both groups who were brought to the hospital by ambulance emergency services were similar: Group 1 (72 in Group 1 and 74 in Group 2) ( $p=0.332)$.

The numbers of unexpected deaths (non-chronic terminal disease and cancer) in Groups 1 and 2 were 72 and 80, respectively. The ratio of witnessed cardiac arrest cases was higher in Group $1(47 \%)$ than Group $2(32 \%)(p=0.043)$. In Group 1, relatives accompanied $50 \%$ of patients to the emergency department, and relatives accompanied $65 \%$ of patients in Group 2. On average, each cardiac arrest patient was accompanied by between two and five relatives $(p=0.034)$ (Table 1$)$. The numbers of relatives of cardiac arrest patients and their degree of affinity to the patients are listed in Table 1.

The average duration of CPR was 37.5 $\pm 9.5 \mathrm{~min}$ in Group 1 and $34.4 \pm 12.5 \mathrm{~min}$ in Group $2(\mathrm{p}=0.047)$. The rate of providing information to relatives about another possible cardiac arrest in the witnessed cardiac arrest cases was higher in Group $1(p=0.011)$ (Table 1). 
Table 4. Comparison of reactions according to the gender

\begin{tabular}{|c|c|c|c|c|}
\hline Reactions & & $\begin{array}{c}\text { Female, } \\
\text { n (\%) }\end{array}$ & $\begin{array}{l}\text { Male, } \\
\text { n (\%) }\end{array}$ & $\begin{array}{l}\text { Total, } \\
\text { n (\%) }\end{array}$ \\
\hline \multirow{8}{*}{$\begin{array}{l}\text { Group } 1 \\
(p=0.376)\end{array}$} & Only cried & $24(68.6)$ & $36(55.4)$ & $60(60)$ \\
\hline & $\begin{array}{l}\text { Damaged } \\
\text { the environment }\end{array}$ & - & $2(3.1)$ & $2(2)$ \\
\hline & Harmed themselves & $2(5.7)$ & $4(6.2)$ & $6(6)$ \\
\hline & $\begin{array}{l}\text { Asked permission } \\
\text { to see their patient }\end{array}$ & $1(2.9)$ & $1(1.5)$ & $2(2)$ \\
\hline & Thanked & $2(5.7)$ & $1(1.5)$ & $3(3)$ \\
\hline & $\begin{array}{l}\text { Remained } \\
\text { unresponsive }\end{array}$ & $3(8.6)$ & $7(10.8)$ & $10(10)$ \\
\hline & $\begin{array}{l}\text { Multiple negative } \\
\text { reactions }\end{array}$ & $3(8.6)$ & $14(21.5)$ & $17(17)$ \\
\hline & Total & 35 & 65 & 100 \\
\hline \multirow{9}{*}{$\begin{array}{l}\text { Group } 2 \\
(p=0.038)\end{array}$} & Only cried & $9(27.3)$ & $8(11.9)$ & $17(17)$ \\
\hline & $\begin{array}{l}\text { Damaged } \\
\text { the environment }\end{array}$ & $1(3)$ & $4(6.0)$ & $5(5)$ \\
\hline & $\begin{array}{l}\text { Harmed } \\
\text { themselves }\end{array}$ & $9(27.3)$ & $14(20.9)$ & $23(23)$ \\
\hline & $\begin{array}{l}\text { Asked permission } \\
\text { to see their patient }\end{array}$ & $1(3)$ & $2(3)$ & $3(3)$ \\
\hline & $\begin{array}{l}\text { Declared idea } \\
\text { of inadequate } \\
\text { intervention }\end{array}$ & $4(12.1)$ & $1(1.5)$ & $5(5)$ \\
\hline & Thanked & - & $2(3)$ & $2(2)$ \\
\hline & $\begin{array}{l}\text { Remained } \\
\text { unresponsive }\end{array}$ & $2(6.1)$ & $3(4.5)$ & $5(5)$ \\
\hline & $\begin{array}{l}\text { Multiple } \\
\text { negative } \\
\text { reactions }\end{array}$ & $7(21.2)$ & $33(49.3)$ & $40(409)$ \\
\hline & Total & 33 & 67 & 100 \\
\hline
\end{tabular}

The relatives in Group 2 expressed more negative reactions (harming themselves and the environment) than those in Group 1 $(p=0.000)$. More relatives in Group 2 than Group 1 also believed that the intervention was insufficient, and they became violent (verbal abuse and physical attacks).The rates of briefings during CPR were $96 \%$ in Group 1 and $51 \%$ in Group 2 ( $p=0.001)$. More relatives in Group 2 than Group 1 committed violence to see their loved ones $(p=0.001)$ (Table 2).

In the first minute after receiving the bad news, the most common response of the majority of the relatives in Group 1 was crying (60\%), whereas the relatives in Group 2 expressed multiple negative reactions $(40 \%)(p=0.001)$.

For both expected deaths and unexpected deaths, more relatives in Group 1 than in Group 2 responded simply by crying $(p=0.027)$ (Table 3). The differences in the reactions of the relatives in Group 1 $(p=0.027)$ and Group $2(p=0.02)$ to expected deaths and unexpected deaths were statistically significant. The results of the comparison of the two groups' reactions to expected deaths $(p=0.001)$ and unexpected deaths $(p=0.001)$ were statistically significant. When both groups were combined, adverse reactions were significantly higher in cases of unexpected deaths $(p=0.048)$.

In Group 1, the difference between reactions, such as crying or expressing multiple negative responses, based on the patient's gender was not statistically significant $(p=0.376)$.The response of most patients' relatives in Group 2 was mainly crying when the deceased was a woman, whereas they showed much more negative reactions when the deceased was a man $(p=0.038)$ (Table 4$)$. Rates of negative reactions were higher in Group 2 compared to Group 1 for both female and male patients $(p=0.001)$. When the data of both groups were combined, the number of negative reactions was higher when the patient was male $(p=0.029)$.

When the data of each group were evaluated separately, the association between a single reaction (crying) and the patient's age (under 46 and over 46 years) was not statistically significant. In Group 2, when the deceased person was older than 46 years, the rate of a single reaction (crying) was higher than the rate of multiple reactions, whereas the rate of multiple diverse reactions was higher when the deceased was less than 46 years old $(p=0.005)$. When the data of

Table 5. Prediction of negative reactions using Multiple Logistic Regression Analysis

\begin{tabular}{|c|c|c|c|c|c|c|}
\hline Variables & & $\begin{array}{c}* * \text { Negative } \\
\text { Reaction }(n=98)\end{array}$ & $\begin{array}{c}\text { *Positive } \\
\text { Reaction }(n=102)\end{array}$ & OR & $95 \%$ GA & $\mathbf{p}$ \\
\hline \multirow[t]{2}{*}{ Age } & $<46$ & $20(20.4)$ & $12(11.8)$ & 1.920 & $0.823-4.479$ & 0.131 \\
\hline & $\geq 46$ & 78 (79.6) & $90(88.2)$ & 1 (reference) & & \\
\hline \multirow[t]{2}{*}{ Gender } & Male & $72(73.5)$ & $60(58.8)$ & 2.114 & $1.09-4.08$ & 0.026 \\
\hline & Female & $26(26.5)$ & $42(41.2)$ & 1 (reference) & & \\
\hline \multirow[t]{2}{*}{ Degree of affinity } & Close & $46(46.9)$ & $53(52.0)$ & 0.970 & 0.530-1.776 & 0.921 \\
\hline & Distant & $52(53.1)$ & $49(48.0)$ & 1 (reference) & & \\
\hline \multirow[t]{2}{*}{ Informing } & Done & $59(60.2)$ & $88(86.3)$ & 1 (reference) & & \\
\hline & Undone & $39(39.8)$ & $14(13.7)$ & 4.963 & $2.380-10.349$ & 0.001 \\
\hline \multirow[t]{2}{*}{ Expected/unexpected death } & Expected & $18(18.4)$ & $31(30.4)$ & 1 (reference) & & \\
\hline & Unexpected & $80(81.6)$ & $71(69.6)$ & 1.576 & $0.762-3.263$ & 0.220 \\
\hline
\end{tabular}


the two groups were compared, the rates of multiple negative reactions for patients older/younger than 46 years were higher in Group $2(p=0.0001)$. The correlation between the patient's age and positivity/negativity of reactions was not statistically significant when we evaluated both groups together $(p=0.096)$.There was no significant association between the degree of affinity (first-degree relatives and others) and the relatives' reactions when the data of both groups were combined $(p=0.478)$.

The analysis of the factors influencing the nature of the reactions revealed that the rate of positive reactions was statistically significant when the relatives were briefed at the start of the CPR and then regularly throughout the CPR procedure $(p=0.001)$. Prediction of negative reactions with help of multiple logistic regression analysis was used to predict negative reactions (Table 5).

\section{Discussion}

Death and subsequent separation can have major adverse effects on the bereaved. People may find it very difficult to cope with the separation. Upon hearing the news of the death, they may exhibit various behaviors, such as violence against health staff and self-harm. Although health staff cannot bring back the deceased patients, by training and changing behavioral patterns, they can minimize violence exhibited by the relatives of the deceased, reduce their grief, and prevent them from self-harming (12).

Although various studies in the literature have focused on the delivery of bad news $(12,13)$ data originating from the emergency services are insufficient. Thus, the results of the present study are important. When delivering bad news, there is general agreement that it is important to have staff who have sufficient knowledge of the interventions performed on the patient and who are qualified to respond to relatives' emotional needs and to answer their questions. Thus, in the present study, emergency medicine physicians delivered the bad news in both groups and performed the resuscitation in both groups.

A high workload because of large numbers of patients in the emergency department, high numbers of unexpected deaths, relatives being unprepared for news of the death, and a lack of experience and training among health staff (14) can negatively affect communication with the patients and relatives. The high rates of negative reactions of the relatives in public hospital emergency departments (Group 2) can be explained by the physician's lack of training in delivering bad news.

According to the literature, the two most common conditions that have an important role in survival are vascular disorders and malignant tumors (15-17). In the present study, the most common detected cause of cardiac arrest was acute artery thrombosis, and the second most common cause was acute-phase chronic diseases. In the literature, the most common underlying causes of in-hospital cardiac arrest are chronic obstructive pulmonary disease, heart failure, malignancy, acute-stage diabetes mellitus and chronic kidney disease, and acute-stage artery diseases (18), which are similar to the results of the present study. In the present study, the underlying causes of all deaths were detected; although Oguzturk et al. (19) reported that the causes of death following cardiac arrest in $12.5 \%$ of cases could not be detected.

It is understandable that first-degree relatives wish to accompany their loved ones to the emergency room, although this is not common practice in developed countries, where large numbers of first-degree relatives and distant relatives are not welcome in the emergency room. The large numbers of people who live in the same household in Turkey and the strong affinities between them can explain why so many relatives accompany patients to the emergency room. The most important reasons of this situation are the large number of people who live in the same house and strong relationships by affinity. In addition, relatives who are not in the emergency room with loved ones may be criticized and partially marginalized. Sometimes these individuals try to show their presence by causing disturbance. This may also explain the violent behavior of some relatives after hearing the news of the death of the family member.

If the deceased patient's gender is excluded, the relatives being well informed can explain the expression of a single reaction (crying) rather than multiple negative reactions. When the patient was male, the provision of a large amount of information led to a decrease in the reactions of the relatives in Group 1 compared to Group 2, but the information provision did not completely suppress negative reactions. The more intense reactions to the death of a male patient are likely due to the patriarchal structure of Turkish society and higher societal value placed on males than females (20). We believe that the higher rates of negative reactions among the relatives in Group 2 both before resuscitation and after delivering the bad news were due to a lack of information provision, which could have prepared relatives for the news. When they are not informed regularly, relatives may insist on seeing their loves ones and become violent if restrained from doing so. In Group 1, allowing the relatives to see their loved ones and informing them during resuscitation decreased the relatives' concerns, made them believe in our care for their family member, and helped them to trust us. The greater number of negative reactions (verbal or physical violence) of the relatives in Group 2 after receiving the bad news confirms the importance of our mind.

Large numbers of unexpected deaths may occur among patients admitted to the emergency department because of sudden morbidity. In the present study, although the negative reactions to unexpected deaths were statistically higher than the reactions to expected deaths, there were less negative reactions in Group 1 due to regularly informing relatives. These findings show that communicating with relatives at regular intervals (during and after resuscitation) after admitting the patient to the emergency room and informing relatives about possible impending death are effective methods to help relatives accept the sad truth of death and avoid potential violence. The higher number of CPR cases in Group 1 was due to the higher number of serious cases admitted to tertiary emergency services. The higher number of expected deaths corroborates our opinion on this issue. We cannot explain the statistically significantly increased duration of CPR in the tertiary emergency services.

The presence of relatives during CPR is a controversial topic (21). Allowing certain family members to be in the resuscitation room and having a designated team member answer their questions might increase their comfort and support them emotionally during cardiac arrest and after resuscitation $(6,7)$. Those who support relatives being present while resuscitation takes place point out that this is the patient's and relatives' fundamental right and that it helps the patient deal with a stressful experience (12). However, the effect of the presence of relatives on the performance of the health staff also needs to be considered. According to some studies, relatives witnessing resuscitation influences health staff positively (21), does not increase the stress level of the individual performing the CPR (22), and helps 
relatives to accept the death of the patient (23). On the other hand, a study aiming to evaluate the psychological effects of witnessed resuscitation on relatives had to be terminated because the staff refused to cooperate with the study staff were unconvinced (24). In the present study, witnessed resuscitation was not permitted in the tertiary emergency departments, but selected relatives were allowed to see their loved ones at least three times for a brief period, were informed about the status of the patient, and were advised to relay this information to other family members. In the secondary emergency services, the relatives were not allowed to witness the resuscitation or see their loved ones because of concerns that this would increase the stress levels of health staff and adversely affect the CPR. This had a statistically significant negative effect on relatives' reactions before, during, and after resuscitation.

\section{Study limitation}

In this study of relatives' reactions to the news of the death of a loved one, the following are important limitations: not considering the age, gender, religion, occupation, level of education, and socio-cultural status of the relatives; not considering the effects of the presence of relatives on the performance of the health staff during resuscitation; not considering cardiac arrest patients younger than 16 years, and not considering the different volume between both groups. An additional limitation is the low numbers of cardiac arrest cases in both groups.

\section{Conclusion}

Other than the deceased patient's gender and degree of affinity, the results showed that various factors, such as the deceased patient's age, cause of death, whether or not the death was expected, condition of the patient upon admittance to the hospital, and duration of the resuscitation, affected relatives' reactions to the news of the patient's death. They also revealed that whether reactions were positive or negative depended on the deceased patient's gender, degree of affinity, frequency and type of information given to the relatives, and whether or not relatives accessed the resuscitation room during resuscitation. The present study shows that allowing relatives to see their loved ones for a brief time before, during, and after resuscitation in the resuscitation room and informing them clearly about the medical interventions can help them to accept death more easily and decrease the number of negative reactions while waiting to hear news.

Ethics Committee Approval: Ethics committee approval was received for this study from the ethics committee of Gaziantep University School of Medicine.

Peer-review: Externally peer-reviewed.

Conflict of Interest: No conflict of interest was declared by the authors.

Financial Disclosure: The authors declared that this study has received no financial support.

\section{References}

1. Ptacek JT, Eberhardt TL. Breaking bad news.A review of the literature. JAMA 1996; 276: 496-502. [CrossRef]

2. Roman EM, Sorribes E, Ezquerro O. Nurses Attitudes to Terminally III. Patients. J Adv Nurs 2001; 34: 338-45.
3. Karakuş G, Öztürk Z, Tamam L. Death and Death Anxiety. Archives Medical Review Journal 2012; 21: 42-79.

4. Mueller PS. Breaking bad news to patients: The SPIKES approach can make his difficult task easier. Postgrad Med 2002; 112: 18. [CrossRef]

5. Ungar L, Alperin M, Amiel GE, Beharier Z, Reis S. Breaking bad news: structured training for family medicine residents. Patient Educ Couns 2002; 48: 63-8. [CrossRef]

6. Bossaert LL. European Resuscitation Council Guidelines for Resuscitation 2015 Section 11. The ethics of resuscitation and end-of-life decisions: 302-311.

7. Compton S, Madgy A, Goldstein M, Sandhu J, Dunne R, Swor R. Emergency medical service providers' experience with family presence during cardiopulmonary resuscitation. Resuscitation 2006; 70: 223-8. [CrossRef]

8. Wells J, Bowers L. How Prevalent is Violence towards Nurses Working in General Hospitals in the UK? J Adv Nurs 2002; 39: 230-40.

9. Al B, Zengin S, Deryal Y, Gökçen C, Arı Yılmaz D, Yıldırım C. Increased Violence Towards Health Care Staff. Eurasian J Emerg Med 2012; 11: 115-24.

10. Steffgen G. Physical Violence at the Workplace: Consequences on Health and Measures of Prevention, Revue European de Psychologie Appliqee 2008; 285-95.

11. Mark SL, Lauren CB, Peter JK, Henry RH, Erik PH, Vivek KM, et al. Adult Advanced Cardiovascular Life Support: 2015 American Heart Association Guidelines Update for Cardiopulmonary Resuscitation and Emergency Cardiovascular Care. Circulation 2015; 132: 444-64. [CrossRef]

12. Hahn S, Hantikainen V, Needham I, Kok G, Dassen T, Halfens RJ. Patient and Visitor Violence in the General Hospital, Occurrence, Staff Interventions and Consequences: A Cross-Sectional Survey. J Adv Nurs 2012; 68: 2685-99. [CrossRef]

13. Meyers TA, Eichhorn DJ, Guzzetta CE, Clark AP, Klein JD, Taliaferro E, et al. Family presence during invasive procedures and resuscitation. Am J Nurs. 2000; 100: 32-43. [CrossRef]

14. Robinson SM, Mackenzie-Ross S, Campbell Hewson GL, Egleston CV Prevost AT. Psychological effect of witnessed resuscitation on bereaved relatives. Lancet 1998; 352: 614-17. [CrossRef]

15. Al B, Sarcan E, Zengin S, Yıldırım C, Kabul S. The public's view of increasing towards healthcare staff. Eurasian J Emerg Med 2015; 14: 19-25. [CrossRef]

16. Schultz SC, Cullinane DC, Pasquale MD, Magnant C, Evans SRT. Predicting in-hospital mortality during cardiopulmonary resuscitation. Resuscitation 1996; 33: 13-7. [CrossRef]

17. Walraven CV, Forster AJ, Parish DC, Dane FC, Chandra KM, Durham MD, et al. Validation of a Clinical Decision Aid to Discontinue In-Hospital Cardiac Arrest Resuscitations. JAMA 2001; 285: 1602-6. [CrossRef]

18. Pattaraarchachai J, Rao C, Polprasert W, Porapakkham Y, Pao-In W, Singwerathum N, et al. Cause-specific mortality patterns among hospital deaths in Thailand: validating routine death certification. Popul Health Metr 2010; 8: 12. [CrossRef]

19. Oğuztürk H, Turtay M, Tekin Y, Sarıhan E. Cardiac Arrests in the Emergency Ward and Our Experiences on the Cardiopulmonary Resuscitation. Kafkas J Med Sci 2011; 1: 114-7 [CrossRef]

20. IIlbars Z. "Family and Tradition", C: 2, Ankara: Family Research Institution Press, 1991.pp.540-44.

21. Herlitz J, Rundqvist A, Aune BS, Lundström G, Ekström L, Lindkvist J. Is there a difference between women and men in characteristics and outcome after in hospital cardiac arrest? Resuscitation 2001; 49: 15-23.

22. Halm MA. Family presence during resuscitation: A Critical Review of the Literature. Am J Crit Care 2005; 14: 494-512.

23. Boyd R, White S. Does Witnessed Cardiopulmonary Resuscitation Alter Perceived Stress in Accident and Emergency Staff? Eur J Emerg Med 2000; 7: 51-3.

24. Doyle CJ. Family participation during resuscitation: an option. Ann Emerg Med 1987; 16: 107-9.[CrossRef] 